\title{
The Role of Human Resource Information System (HRIS) in Organizations: A Review of Literature
}

\author{
Halil Buzkan \\ EpokaUniversity, Tirana,Albania; hbuzkan@epoka.edu.al
}

\author{
Doi:10.5901/ajis.2016.v5n1p133
}

\begin{abstract}
The information systems (IS) are becoming very important for the organizations. Therefore over the last decade's wise companies started to become aware of those technologies and they tend to use it for their competitive advantage. The human resource information systems (HRIS) as a function of IS are also become inevitable for organization, because they know that their human resources (HR) are one of the most important factor in their success, therefore to implement a human resource information system in their human resources will help the organizations reach their goals easily. In this study a literature review related to HRIS is done and it is revealed its importance for the organizations.
\end{abstract}

Keywords: Information Systems, human resource information systems, human resources, literature review.

\section{Study Background}

The technological developments in the businesses have forced the companies to adopt the new technologies in order to survive in the competitive market (Arnerić, Praničević, \& Tadić). Therefore over the last decade's information systems have become very important for organizations (Desanctis, 1986). As the world has been globalized day by day, the daily problems have become more complex for businesses, which in turn urged companies to have and to adopt new technologies and innovations to solve these problems. Due to the information technology avaliability, the human resource functions have been transformed surprisingly, to design and improve the efficiency of administration and services. Information systems are often considered as a driver of change within HR department of the organizations, as it enables to resolve the human resource related problems by the use of information technologies (Haines \& Lafleur, 2008).

On the other hand information technology is very important for managers as a tool that can be used to manage the organization and particularly in human resource functions in order to increase the capabilities of the organization (Tansley \& Watson, 2000). So that human resource management functions have not passed over such potential, and a human resource information system usage has occurred (CedarCrestone, 2009-2010).

Human resource information systems are also one of the most important technologies which have been developing with information technologies as a function of human resource management (HRM). A HRIS is an integrated software, hardware, support functions, system policies and procedures into an automated system process that support the strategic and operational process of HR departments and their managers (Chauhan, Sharma, \& Tyagi, 2011).

HRIS are systems that used to collect, to record and store, to analyse and retreive, the data related to an organization's human recources. The collection of data may consist of salary and payroll, compensation, leave, performance appraisals, accidents, retirement, employee benefits etc. Traditionally, the functions of HR departments are common to all organizations. Meanwhile, it is important to note that the duties of human resource manager's were to sustain the functions of human resource departments which were conducted manually before the use of HRIS. Researchers indicates that the information systems can decrease the cost of administrative works, increase productivity, shortened the time of response, improve decision-making, and improve the quality of the customer service all at the same time (Desanctis, 1986) (Hussain, Wallace, \& Cornelius, 2007) (Ball, 2001). In addition, (Yeung \& Brockbank, 1995) states that the decreasing of cost, higher quality services, and cultural change are the three main reasons for the need of IS-driven HR solutions for the companies (Yeung \& Brockbank, 1995). To reduce the manual workload of administrative activities, organizations began to electronically automate many of the processes by introducing specialized human resource management systems (HRMS) in which, the HR executives rely on internal or external IT professionals to develop and maintain an integrated human resource management system. Accordingly, the technologies are used to research and develop a conceptual strategic framework by improving strategic human resource management and by identifying the related issues of HRISs (Perrin, 1992). 


\section{Human Resource Information Systems In Organizations}

\subsection{Definition of HRIS}

There are different definitions of human resource information systems (HRIS) as follow, Kovac \& Cathcart,(1999) defines "HRIS as a systematic procedure for collecting, storing, maintaining, retrieving, and validating data needed by organization about its human resources, personnel activities, and organization unit characteristics (Kovach \& Cathcart, 1999)." In another research Tannenbaum, (1990) defines "A human resources information system is a technology-based system used to acquire, store, manipulate, analyze, and retrieve, and distribute pertinent information regarding an organization's human resources (Tannenbaum, 1990)." In addition, HRIS is a connection between HRM and information technology (IT). On the other hand human resource information system also includes the people, policies, procedures and data that required to manage human resources functions other than the applications that comprise the technical part of the system as hardware and software applications are not only limited with the computer hardware and software (Hendrickson, 2003).

Furthermore HRIS is not only concentrated on HR management issues but also it is concentrated on the organizational objectives. Therefore an HRIS is more than recording the files to the computer, it is an approach that store, record, analyze and control the data that related to organization human resources (Bingöl, 2006, p. 557).

\subsection{Historical Overview}

The very first mechanized human resource comes from 1940's and from 1950's it starts to run sorting and tabulating equipment, in those days computers had very limited thing to do, like monitoring employee record and payroll activities. In the 1960's personnel department started to take part in the technological improvement occurring in finance and accounting area, until late 1960's the only computer based applications in personnel department were payroll and basic employee record keeping. During 1970's some large companies has developed personnel data system. Studies of 1980 's shows that, the firms that have human resource information systems are about $40 \%$, while, the majority of companies which do not have are interested to obtain one (Desanctis, 1986).

Starting from 1980's large organizations has established a HRIS in their human resources department, to meet their needs. Apart from IS, the development of HRIS has been made possible by advanced mainframe software technology such as; packaged applications, database management systems.

The developing a HRIS within the organization has been improving much after 1978, however, most of the organizations had not developed a HRIS till 1980. The maturity of a HRIS which is the professional use of the system in an organization depends on the organization size and the level of its management.

The typical HRIS consist of 4 to 5 application modules such as; compensation and equity monitoring, which is considered to be the most important module, that followed by benefit administration module, applicant flow module, and the human resource control module (Yeung \& Brockbank, 1995). Before the sustained improvement in the HRIS.The functions of the HRIS used to be under the IS area to reach their goals. For example, HRIS was maintained and developed by IS technical staff before, meanwhile, in last decades all responsibilities related to human resources has been transferred to human resources personnel.

\subsection{Functions of HRIS}

HRIS must meet the needs of different levels of the management within the organization such as; HR professionals, managers in functional areas and employees. A functional HRIS enables an integration of policies and procedures used to manage the firm's human resources as well as the procedures required to operate the computer software and hardware applications (Hendrickson, 2003). The most important functions of HRIS are; to integrate the technologies of $\mathrm{HR}$, to increase the efficiency, to increase effectiveness, and to enable usage of IT. Accordingly, the HRIS provides a significant support to human resource functions in regard to the impact of information technology on human resources ( Boateng, 2007).

\section{HRIS Model}

HRIS has been designed for human resource management to realize the strategic objectives of the organizations, to 
improve its productivity and proficiency by increasing the efficiency and effectiveness of daily functions. HRIS has given an opportunity to the organizations to solve and manage their different issues and processes related to the management of employees. On the other hand HRIS also used for different purposes, particularly in human resource processes as recruitment and selection, performance evaluation, compensation and benefits, training and development, health and safety, employee relations and legal issues, and for retention and work life balance (Ensher, Neilson, \& Grant-Vallone, 2002).

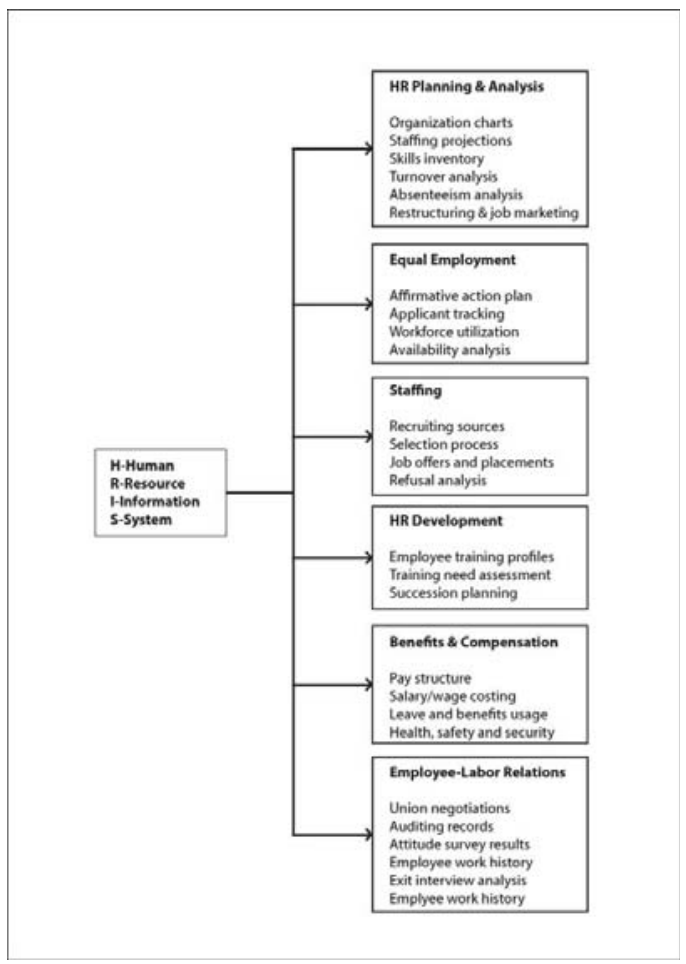

Figure 1: Model of Human Resource Information System (HRIS) (Aggarwal \& Kapoor, 2012)

\section{Advantages and Disadvantages of HRIS (Benefits and Drawbacks of HRIS)}

Contemporary human resource information systems that are comprehensive, accurate and accessible are used to ease jobs of HRM such as; recording and working employee related data. HRIS is aimed to support operational decision making, to evaluate programs and routine daily operations (Chauhan, Sharma, \& Tyagi, 2011).

Table 1: The advantages and Disadvantages of HRIS presented by scholars:

\begin{tabular}{|l|l|l|l|}
\hline Authors & Year & Advantages & Disadvantages \\
\hline Chandra & 2009 & To improve planning and programming by using decision & \\
& support software. & \\
& Faster information processing and feedback. & \\
& Faster decisions making & \\
& More active communication at all levels \\
& To decrease administrative and HR costs. \\
& Reliability of information. \\
& Competitive advantage for organization \\
& More sophisticated reports about HR processes (Chandra, & \\
\hline
\end{tabular}




\begin{tabular}{|l|l|l|l|}
\hline Desanctis & 1986 & 2009). & \\
\hline Beadles et al. & 2005 & $\begin{array}{l}\text { Reducing the HR cost by automating information. } \\
\text { Reducing the need for large numbers of employees } \\
\text { (Beadles II, Lowery, \& Johns, 2005). }\end{array}$ & $\begin{array}{l}\text { Its initial investment cost and training } \\
\text { costs of users to convince the top } \\
\text { managers to acquire an HRIS } \\
\text { (Desanctis, 1986). }\end{array}$ \\
\hline Akansha Chauhan & 2011 & $\begin{array}{l}\text { HRIS can assist human resource management in different } \\
\text { aspects, particularly by streamlining workflow processes } \\
\text { through control processes in their day-to-day tasks } \\
\text { (Chauhan, Sharma, \& Tyagi, 2011). }\end{array}$ & $\begin{array}{l}\text { Small firms cannot afford the cost and } \\
\text { the risk of implementing new software } \\
\text { (Ngai \& F.K.T., 2006). }\end{array}$ \\
\hline Ngai and Wat & 2006 & \multicolumn{2}{|l}{} \\
\hline
\end{tabular}

\section{Role of HRIS Usage, Implementation and Its Impact}

The literature states that HRISs are generally used for administrative purposes. For instance, Ball (2000) have found out that the organizations that have more employees are tend to hold their information electronically both on the individual and organizational level. Similarly, the information analysis would occur with the human resource information systems (HRIS) in the organizations that have more employees. In the use of HRIS, most of the organizations with an employee of less than 500 use the core modules of HR rather than training and recruitment modules. Lastly, author indicates that the time and attendance was the most frequently integrated additional modules (Ball, 2001).

Furthermore the more people employed by the organization the less likely it was to adopt additional non-core HR modules, and the organizations that have newly purchased HRIS are tend to buy additional non-core HR modules (Ball, 2001).

Additionally, Hussein et al, (2007) indicates that in the practice of HRIS there are small differences between smallmedium and large organizations. Thus, it adds value to company regardless to its size by means of strategic use of HRIS through HR profession. Moreover, strategic use of HRIS enhances the perceived standing of HR professionals within the organization by being more important than ever (Hussain, Wallace, \& Cornelius, 2007). In the globalizing world any company cannot omit the role of HRIS in their human resources. Organizations use HRIS for different kind of purposes as human resources planning, recruitment, selection, training and development, payroll benefits and so on.

Accordingly, the use of HRIS become part of corporate culture providing valuable information in managing one of the most valuable asset of an organization and thus, have been used as a competitive advantage. This has been also emphasized as main advantage of an organization by Totty (2001) where HRIS is cost reductive, as the replacement of the people with software is less costly (Kovach \& Cathcart, 1999).

\section{Conclusion}

According to the studies of scholars as stated in the literature review, the implementation of the IS along with its advantages and disadvantages within the organizations is inevitably important to survive in the global competitive market. Thus, for the organizations that are aware of its human resources value, an efficient use of IS in HRM and specifically for strategic objectives and strategic decision making processes of the organization will sustain everlasting success in their operations. The strategic implementation of HRIS would improve the perceived standing of HR professionals and executives within their organizations as HRIS provides added value and increases the status of the HR profession as a whole. Additionally, HRIS may lead to sustained competitive advantage through the creation and deployment of knowledge based resources for the organization.

As stated by Ball (2002) the use of HRIS differs for companies with different sizes. Where, large scale companies use HRIS more effectively compared to the small-medium sized ones. In contrast Husain et.al (2006) indicates it become a norm irrespective to company size. Thus, it can be concluded that the use of HRIS have gained dramatic stage in use through the period of 2002 to 2006. Apparently, Desanctis (1986), (Wickramaratna, 2011) and (Benfatto, 2010) argue that most of the organizations use the HRIS for their administrative purposes other than for their strategic or organizational purposes.

To sum up, the use of HRIS is common to almost all organizations but not in the same level. Some organizations 
use HRIS for their administrative tasks while others use both for administrative and strategic tasks. Accordingly, the use of HRIS is considered to be the key driver for an acting organization in the competitive environment.

\section{References}

Boateng, A.-A. A. (2007). The Role of Human Resource Information Systems (HRIS) in Strategic Human Resource Management (SHRM). Doctoral Thesis.

Ngai, E., \& F.K.T., W. (2006). Human resource information systems: a review and empirical analysis. Personnel Review, 35(3), 297-314.

Aggarwal, N., \& Kapoor, M. (2012). Human Resource Information System (HRIS)- Its role and importance in Business Competitiveness. GIAN JYOTI E-JOURNAL, 1(2).

Arnerić, J., Praničević, G. D., \& Tadić, I. (n.d.). The Use Of Human Resource Information System (HRIS) In Croatian Hotels On the Adriatic Coast: A Survey. Labor Economics/Human Resources.

Ball, K. S. (2001). The Use Of Human Resource Information Systems: A Survey. Personnel Review, 30(6), 677-693.

Beadles II, N. A., Lowery, C. M., \& Johns, K. (2005). The Impact of Human Resource Information Systems: An Exploratory Study in the Public Sector. Communications of the IIMA, 5(4), 39-46.

Benfatto, M. C. (2010, June 25). Human Resource Information Systems and the performance of the Human Resource Function. Doctoral Thesis. Rome.

Bingöl, D. (2006). Insan Kaynaklari Yönetimi. Istanbul: ARIKAN Basim Yayim Dagitim Ltd. Sti.

CedarCrestone, C. (2009-2010). CedarCrestone 2009-2010 HR Systems Survey: HR Technologies, Deployment Approaches, Value, and Metrics. U.S.A.: 2009 CedarCrestone, Inc.

Chandra, R. P. (2009). Role of HRIS in improving Modern HR operations. Advances In Management., 2(12), 21-24.

Chauhan, A., Sharma, S. K., \& Tyagi, T. (2011). Role of HRIS in Improving Modern HR Operations. Review of Management, 58-70.

Desanctis, G. (1986). Human Resource Information Systems; A Current Assessment. . MIS Quarterly, 15-27.

Ensher, E. A., Neilson, T. R., \& Grant-Vallone, E. (2002). Tales From The Hiring Line: Effects of the Internet And Technology On HR Processes. Organizational Dynamics, 31(3), 224-244.

Haines, V. Y., \& Lafleur, G. (2008). Information technology usage and human resource roles and effectiveness. Human Resource Management, Wiley Periodicals, Inc., 525-540.

Hendrickson, A. R. (2003). Human Resource Information Systems: Backbone Technology of Contemporary Human Resources. Journal of Labor Research, XXIV(3), 381-394.

Hussain, Z., Wallace, J., \& Cornelius, N. E. (2007). The use and impact of human resource information systems on human resource management professionals. Information \& Management, 74-89.

Kovach, K. A., \& Cathcart, C. E. (1999). Human Resource Information Systems (HRIS): Providing Business with Rapid Data Access, Information Exchange and Strategic Advantage. Public Personnel Management, 28(2), 275-282.

Perrin, T. (1992). Priorities for competitive advantage: A wordlwide Human Resource Study. New York: Towers Perrin.

Tannenbaum, I. S. (1990). Human Resource Information Systems: User Group Implications. Journal of System Management, 40(1), 2736.

Tansley, C., \& Watson, T. (2000). Strategic exchange in thedevelopment of Human Resource Information Systems (HRIS). New Technology, Work and Employment 15:2, 108-122.

Wickramaratna, U. C. (2011, February 28). The Role Of Human Resource Information Systems In Human Resource Planning In Private Sector Organisations In Sri Lanka. Doctoral Thesis.

Yeung, A., \& Brockbank, W. (1995). Reengineering HR through Information Technology. Human Resource Planning, 2(18), 24-37. 
